\title{
RADIO PICTURE OF THE SUN AT 3.2-CM WAVELENGTH
}

\author{
V. v. VITKEVICH, A. D. KUZ'MIN, A. E. SALOMONOVICH, AND V. A. UDAL'TSOV \\ Academy of Sciences, Moscow, U.S.S.R.
}

\section{METHOD OF OBTAINING RADIO PICTURE}

In 1957 July the two-dimensional intensity distribution of radio emission over the solar disk was determined at $3.2-$ and $10-\mathrm{cm}$ wavelengths. The observations were carried out on the radio telescope $31 \mathrm{~m}$ in diameter at the Crimean Radio Astronomical Station of the Physical Institute of the Academy of Sciences of the U.S.S.R. The radio telescope was an immovable parabolic reflector with the axis set in the meridian plane on 22-degrees declination [1]. Scanning the pattern of the radio telescope in the declination range \pm 32 minutes of arc to obtain the intensity distribution was done by setting the feed and preamplifier on a movable carriage reciprocating near the focal plane. In combination with the sun's daily movement it provided the twodimensional solar distribution along a zigzag line. These sections gave the radio picture.

\section{RESULTS OF OBSERVATIONS AT 3.2-CM WAVELENGTH}

A small beamwidth at a wavelength of $3.2 \mathrm{~cm}$ (half-power beam angle about 6 minutes of arc) gave us a detailed picture of radio-brightness distribution (radio picture). Fig. $1(a-d)$ showed a series of radio isophotes constructed for $3.2-\mathrm{cm}$ wavelength on records made between July 13 and 25 . These records were not corrected for the smoothing effect caused by the pattern beamwidth. The contours of the visible solar disk, sunspot groups, and protuberances were also plotted according to the data of the Mountain Astronomical Station (GAO). It can be seen from the figure that steady regions of increased radio brightness across the solar disk were observed. The comparison of their position with sunspot groups recorded on the observing days revealed that the majority of them might be associated with definite sunspot groups.

Comparison of daily radio pictures showed that owing to the sun's rotation the position of the regions of increased radio brightness changed together with the position of the corresponding sunspot groups.

Table I gives the maximum values of the sunspot areas $S_{p_{\max }}$ marked on the days of observations across the visible disk and the steady regions of increased radio brightness (I-IX) associated with sunspot groups. The table shows that only sunspot groups with $S_{p_{\text {cax }}}>100$, as a rule, were associated with the bright regions. 

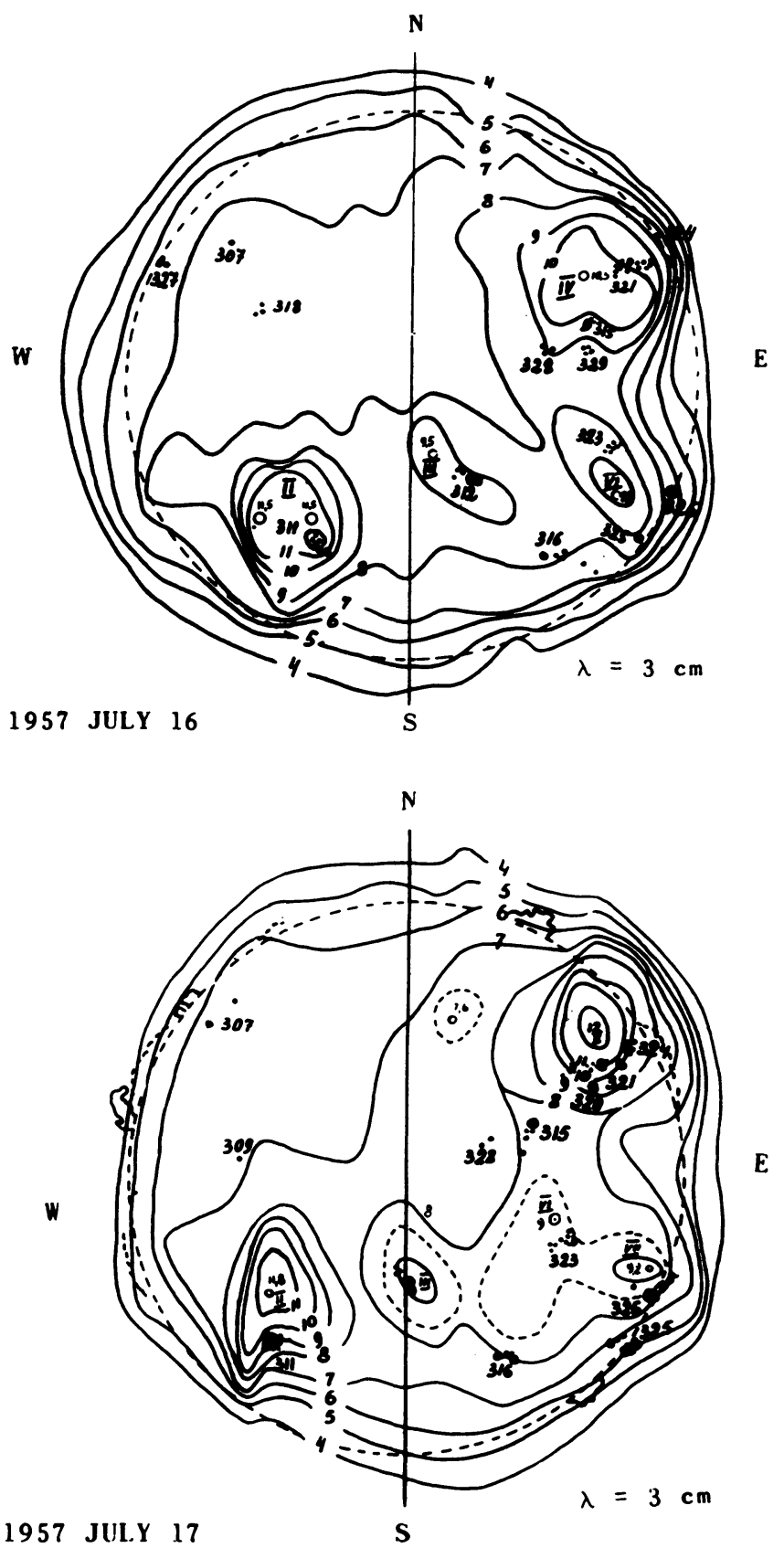

1957 JUL.Y 17

FIG. 1a-d. Radio pictures of the sun at a wavelength of $3.2 \mathrm{~cm}$ for July 16 to 19 . The figures on the picture signify the antenna temperature in units of $10^{3} \mathrm{~K}$. The bright regions and the sunspot groups are marked by numbers. 
NO. 23
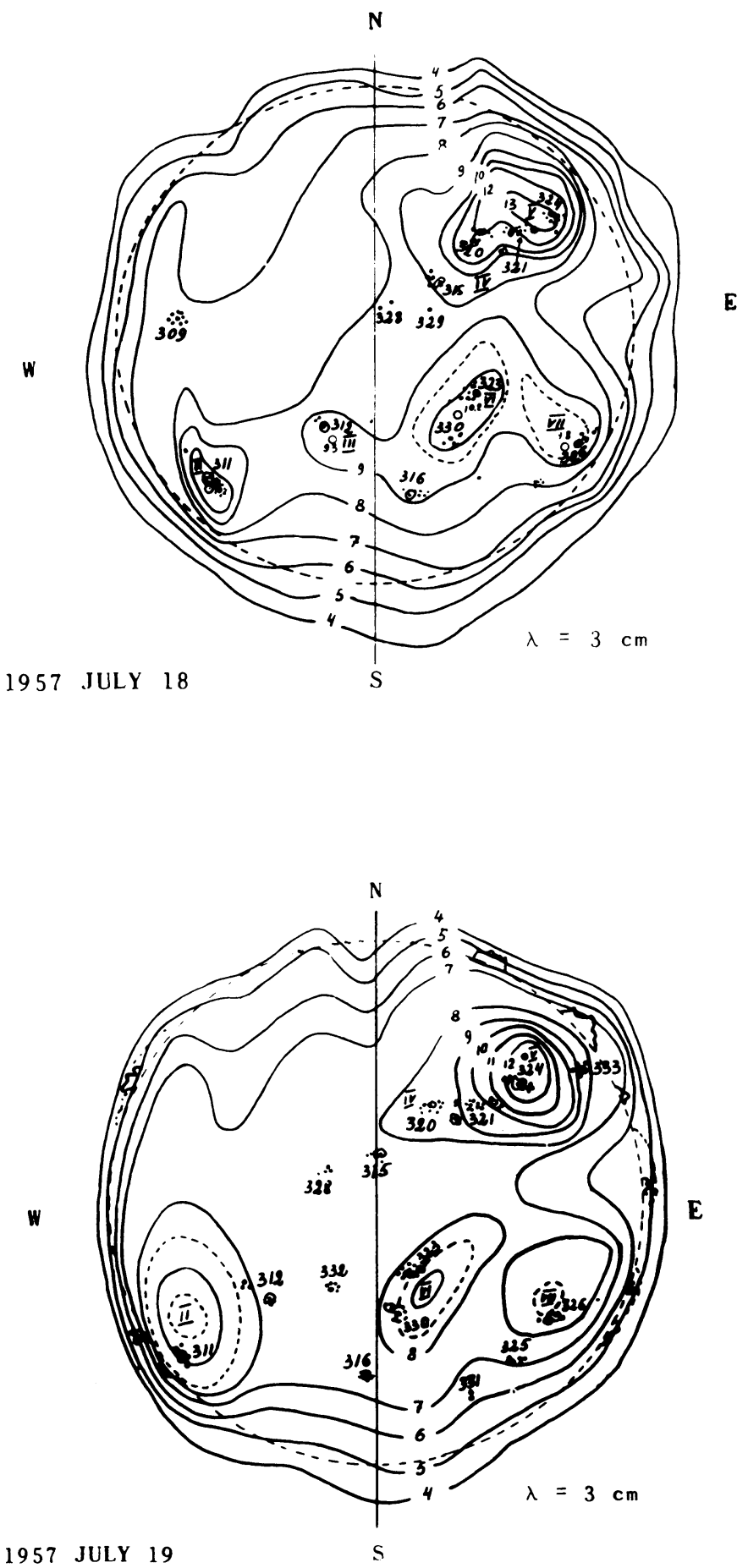
TABLE I

\begin{tabular}{|c|c|c|c|c|}
\hline $\begin{array}{l}\text { Number of } \\
\text { Sunspot } \\
\text { Groups }\end{array}$ & $\begin{array}{l}\text { Date of Ap- } \\
\text { pearance on } \\
\text { Solar Disk }\end{array}$ & $\begin{array}{c}\begin{array}{c}\text { Date } \\
\text { of }\end{array} \\
\text { Disappearance }\end{array}$ & $\begin{array}{l}\text { Maximum Area } \\
\text { of Sunspot } \\
\text { Groups }\end{array}$ & $\begin{array}{c}\text { Bright Regions } \\
\text { Associated with } \\
\text { Groups }\end{array}$ \\
\hline $\begin{array}{l}302 \\
307 \\
309 \\
311 \\
312\end{array}$ & $\begin{array}{l}* \\
* \\
* \\
*\end{array}$ & $\begin{array}{rr}\text { July } & 17 \\
19 \\
19 \\
21 \\
24\end{array}$ & $\begin{array}{r}153 \\
71 \\
35 \\
760 \\
188\end{array}$ & II \\
\hline $\begin{array}{l}314 \\
315 \\
316 \\
317 \\
318\end{array}$ & $\begin{array}{c}\stackrel{*}{*} \\
\stackrel{*}{*} \\
\text { July }^{*} 14\end{array}$ & $\begin{array}{c}14 \\
t \\
25 \\
14 \\
17\end{array}$ & $\begin{array}{r}9 \\
850 \\
239 \\
3 \\
43\end{array}$ & IV \\
\hline $\begin{array}{l}319 \\
320 \\
322 \\
323 \\
324\end{array}$ & $\begin{array}{l}14 \\
14 \\
15 \\
16 \\
16\end{array}$ & $\begin{array}{r}16 \\
t \\
17 \\
t \\
t\end{array}$ & $\begin{array}{r}16 \\
390 \\
14 \\
160 \\
575\end{array}$ & $\begin{array}{c}\text { V } \\
\text { VI } \\
\text { V }\end{array}$ \\
\hline $\begin{array}{l}325 \\
326 \\
327 \\
328 \\
329\end{array}$ & $\begin{array}{l}16 \\
16 \\
16 \\
16 \\
16\end{array}$ & $\begin{array}{r}24 \\
t \\
17 \\
20 \\
19\end{array}$ & $\begin{array}{r}125 \\
592 \\
36 \\
20 \\
12\end{array}$ & VII \\
\hline $\begin{array}{l}330 \\
331 \\
332 \\
333 \\
334\end{array}$ & $\begin{array}{l}18 \\
18 \\
19 \\
19 \\
20\end{array}$ & $\begin{array}{r}\dagger \\
20 \\
21 \\
+ \\
+\end{array}$ & $\begin{array}{r}274 \\
10 \\
19 \\
603 \\
992\end{array}$ & $\begin{array}{l}\text { VI } \\
\text { VIII } \\
\text { IX }\end{array}$ \\
\hline $\begin{array}{l}335 \\
336 \\
337 \\
338 \\
339\end{array}$ & $\begin{array}{l}20 \\
21 \\
21 \\
21 \\
22\end{array}$ & $\begin{array}{r}24 \\
\dagger \\
24 \\
22 \\
23\end{array}$ & $\begin{array}{r}93 \\
45 \\
25 \\
1 \\
4\end{array}$ & \\
\hline $\begin{array}{l}340 \\
341 \\
342\end{array}$ & $\begin{array}{l}23 \\
23 \\
23\end{array}$ & $\begin{array}{r}\dagger \\
+ \\
+\end{array}$ & $\begin{array}{r}370 \\
9 \\
4\end{array}$ & \\
\hline
\end{tabular}

* To the moment of beginning of observation (July 13), the sunspot group was on the solar disk.

$\dagger$ To the end of observation (July 25), the sunspot group stayed on the solar disk.

Fig. $2(a-c)$ contrasts antenna temperatures of the centers of the bright regions with sunspot areas for various days. In five cases out of nine a sharp temperature decrease in the regions was observed, which had begun 1 to 5 days before the reduction of sunspot area. Those cases were the regions II, III, IV, V, and VI. In three cases-VII, VIII, and IX-such regularity failed. It should be noted that in the last cases referred to, the bright regions appeared on the last days of observation; and the decrease of sunspot area had not yet been observed. Consequently, the last cases might not contradict the first five cases. Only in one case (I) might one speak of simultaneous decay of the bright region and the sunspot area.

The directivity of bright region emission was determined by comparing the 
temperature (referred to the area of the group or groups*) with the distance from the center of the disk. Within the period of observation the sunspot groups lay at distances of $0.2 R_{\odot}$ to $1.0 R_{\odot}$ from the center of the disk. The comparison showed no dependence of the temperature of the bright region on distance from the center of the disk.
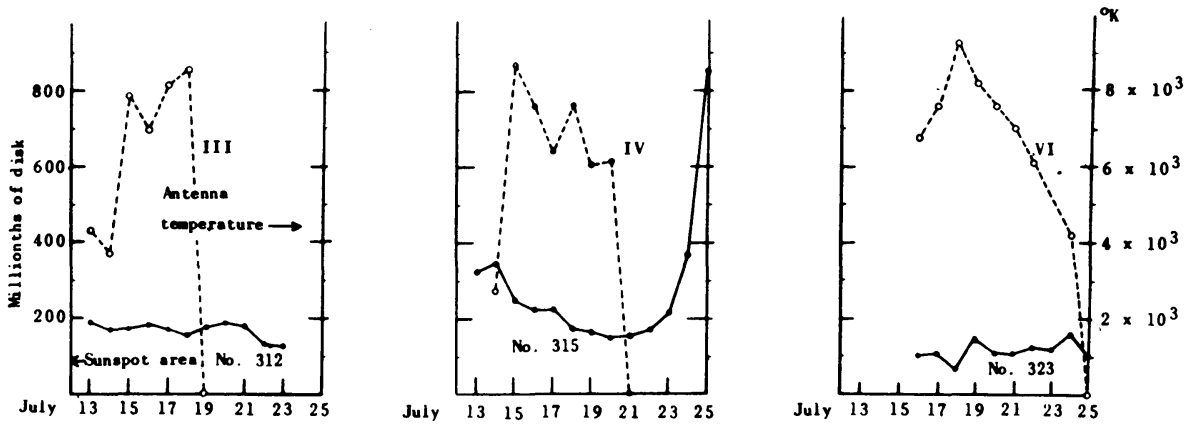

FIg. 2. Antenna temperatures of bright regions (I-IX) and the areas of the corresponding sunspot groups for one and the same days on July 13 to 25 .

The measurement of the difference between current heliographic coordinates of regions and the corresponding sunspot groups determined the upper limit $h$ of the height of bright regions above the photosphere. Since differences were not detected across the middle part of the solar disk, to an accuracy \pm 5 degrees, it might be considered that $h / R_{\odot}$ did not exceed the value 0.09 . An examination of the radio pictures obtained within the period of observation shows a considerable extension of bright regions in comparison with the corresponding sunspot groups. This effect, at least in some cases, might not be explicable by aerial smoothing, since rather narrow regions were observed side by side with very extended regions.

The comparison of coordinates of sunspot groups with maxima of bright regions showed in some cases a significant difference in the position. The difference was not strictly constant but changed from day to day.

An attempt was made to compare bright regions with prominences. Within one period in July (from the thirteenth to the twenty-fifth) there were recorded 114 cases of appearance of prominences.

Of those cases 51 had a brightness of 3 units; in 42 cases, the prominences had area $S>100$ millionths of the disk; two prominences were especially great-with the area more than $10^{3}$ millionths.

In two cases we could not exclude a connection between prominences and increased radio brightness. In all other cases, including the great prominences mentioned above, it was impossible to find any connection between the presence of prominences and bright regions.

It should be observed that the conclusion about the connection of the radio emission at $3-\mathrm{cm}$ wavelength with prominences [2] ought to be made more

* This was done to exclude dependence upon the area of the sunspot group. 
precisely. Apart from the bright regions marked I-IX, within the period of observation on separate days there were recorded seven bright regions that were not associated with sunspot groups. These regions lived 1 to 2 days; three of them could not be associated with any visible formations.

\section{RESULTS OF OBSERVATION ON 10-CM WAVELENGTH}

Fig. $3(a$ and $b$ ) gives a series of radio isophotes for $10 \mathrm{~cm}$ constructed in the same way as at $3.2 \mathrm{~cm}$ (Fig. 1). According to the figure, an irregular distribution of radio brightness across the sun's disk was observed at $10 \mathrm{~cm}$, too. Owing to a large beamwidth (half-power beam angle 15 minutes of arc), the possible separate active regions combined into one large bright region.

The comparison of Fig. 1 with Fig. 3 shows that there was a series of days (July 17, 18, and 19, for instance) when the form and position of the bright region at $10-\mathrm{cm}$ wavelength corresponded approximately with $3.2-\mathrm{cm}$ regions subjected to smoothing by the $10-\mathrm{cm}$ antenna pattern. It enables one to suppose the existence of separate bright regions at $10 \mathrm{~cm}$, which apparently were near the sunspot groups and $3-\mathrm{cm}$ bright regions.

Comparison of $10 \cdot \mathrm{cm}$ pictures obtained on various days showed a drift in accordance with the sun's rotation.

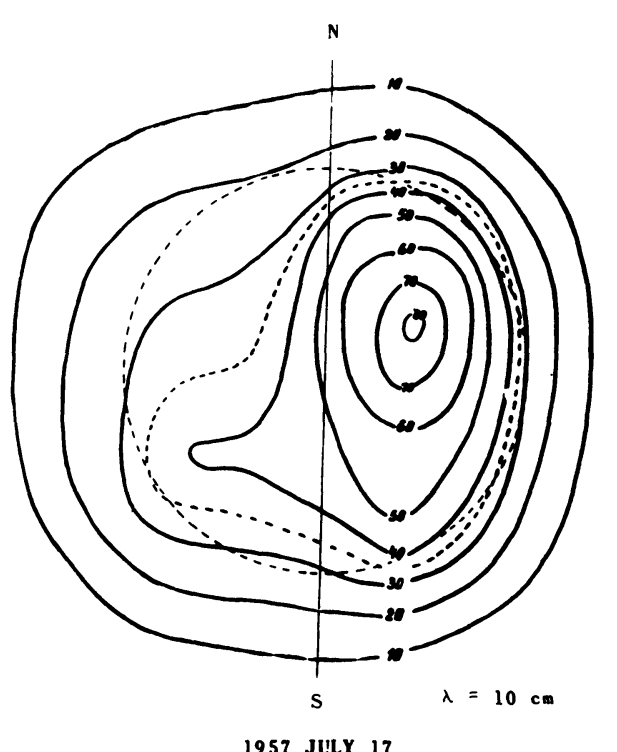

1957 JULY 17

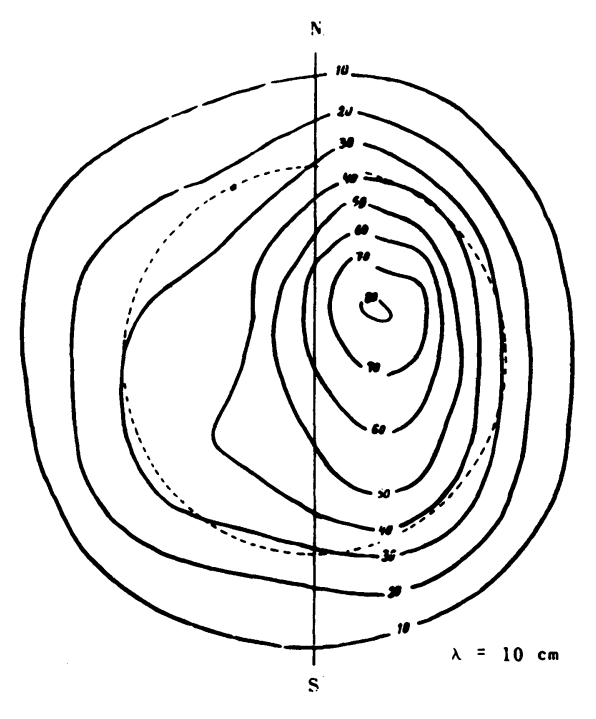

1957 JULY 18

Fig. $3 a$ and $b$. Radio-brightness distribution of the sun at $10-\mathrm{cm}$ wavelength, July 17 to 18 .

\section{CONCLUSIONS}

1. The presence of formations in the solar atmosphere situated at a height less than $0.1 R_{\odot}$ and responsible for increased radio emission in that range might be considered to be a settled problem. 
2. The regions of increased radio brightness drifted across the solar disk together with sunspot groups, and the majority of them, apparently, were associated with the groups. Only great sunspot groups (areas greater than 100 millionths) were associated with regions of increased radio brightness.

3. The directivity of bright regions in the range $(0.2-1) R_{\odot}$ was not observed.

4. The characteristic feature of many bright regions was a shorter life than that of the corresponding sunspot group.

5. The projected areas of bright regions on the photosphere exceeded the area of the corresponding sunspot groups in a number of cases. The maxima of those projections did not always coincide with the group exactly. The last circumstance showed that the bright regions associated with sunspot groups could not be identified with the radiation of the sunspots themselves.

6 . It might be considered to be a settled problem that bright regions at $3.2 \mathrm{~cm}$ were not associated with the appearance of prominences.

7. Bright regions at $10 \mathrm{~cm}$ were associated with bright regions at $3.2 \mathrm{~cm}$ although the relationship was not strict.

\section{REFERENCES}

[1] Vitkevich, V. V., and Udal'tsov, V. A. Radiotekh. i Elekt. 2, 1548, 1957.

[2] Troitskii, V. S., Zelinskaia, M. R., Rachlin, V. L., and Bobrik, V. T. Transactions of the Fifth Conference on Cosmogonical Questions. Moscow (Acad. Sci. U.S.S.R. Press), 1956, p. 182. 